\title{
Desmoid Tumor of the Facet Joint: A Case Report
}

\author{
Han Ga Wi Nam, Seung-Myung Moon, Sei-Woong Jeon, Hyung Sik Hwang \\ Department of Neurosurgery, Dongtan Sacred Heart Hospital, College of Medicine Hallym University, \\ Hwaseong, Gyeonggi, Republic of Korea
}

Desmoid tumors represent a particular type of fibromatosis. The common sites for extra-abdominal desmoid tumors, known as aggressive fibromatosis, are the shoulder, chest wall, and thigh. Desmiod tumors are rare at facet joints of the spine. We describe a patient with a desmoid tumor of a lumbar facet joint.

Key Words: Desmoid tumor • Facet joint $\cdot$ Fibromatosis $\cdot$ Lumbar spine

\section{INTRODUCTION}

Desmoid tumors were first described by McFarlane in $1832^{20)}$. These tumors represent a particular type of fibromatosis $^{1)}$. They are rare, with an estimated incidence of 2-4 cases per million population per year ${ }^{16}$. Common sites for extraabdominal desmoid tumors are the shoulder, chest wall, and thigh $^{22}$. Reports on only a few cases of spinal desmoid tumors have been published in the neurosurgical and spine-related literature $^{9,20)}$. Herein, we describe a patient with a desmoid tumor of a lumbar facet joint.

\section{CASE REPORT}

A 32-year-old man was admitted to our hospital for diagnosis and treatment of lower back pain, both buttock pain, and radiating pain in the left leg that were present for 1 month. He was a computer programmer who had experienced a traffic accident as a passenger 1 year ago, but he had no history of spine surgery. He had undergone nerve blocks several times for the treatment of pain. However, the treatment had had little effect.

Computed tomography (CT) images of the lumbar spine show-

- Received: April 22, 2013 - Revised: May 26, 2013

- Accepted: May 29, 2013

Corresponding Author: Seung-Myung Moon, MD

Department of Neurosurgery, Dongtan Sacred Heart Hospital, College of Medicine, Hallym University, 40 Sukwoo-dong, Hwaseong-si, Gyeonggi-do, 445-170, Republic of Korea

Tel: +82-31-8086-2412, Fax: +82-31-8086-2029

E-mail: nsmsm@hallym.ac.kr ed a smooth, low-density area at the superior and inferior articular process of the left L3-4. Homogeneous enhancement was noted after contrast media injection, with pressure erosion of the facet joint and left lateral lamina (Fig. 1A, B, C). On axial T1- and T2-weighted magnetic resonance imaging (MRI) scans, an intermediate-signal intensity mass of approximately $1.7 \times 1.2 \times 1.8 \mathrm{~cm}$ was seen in the left $\mathrm{L} 3-4$ paraspinal
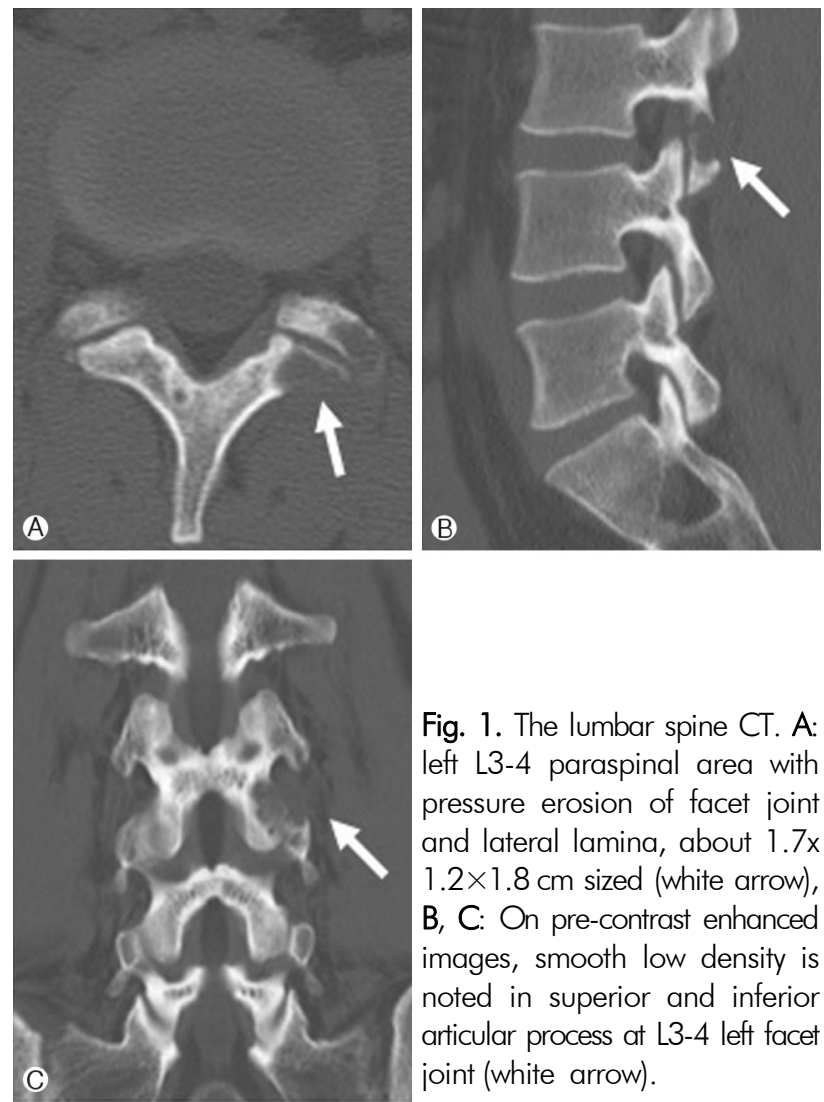

Fig. 1. The lumbar spine CT. A: left L3-4 paraspinal area with pressure erosion of facet joint and lateral lamina, about $1.7 x$ $1.2 \times 1.8 \mathrm{~cm}$ sized (white arrow), B, C: On pre-contrast enhanced images, smooth low density is noted in superior and inferior articular process at L3-4 left facet joint (white arrow). 

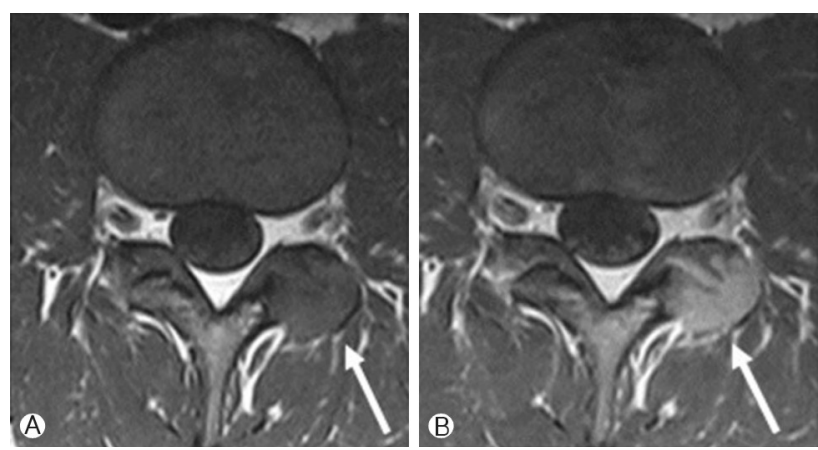

Fig. 2. On axial T1 weighted magnetic resonance imaging (MRI), A: intermediated signal intensity mass, measured about $1.7 \times$ $1.2 \times 1.8 \mathrm{~cm}$ sized, is seen in L3-4 paraspinal area (white arrow). B: After contrast media injection, strong enhancement is noted (white arrow).

area. Strong enhancement was noted in the same region after contrast media injection (Fig. 2A, B).

The patient underwent left L3-4 partial facetectomy without internal fixation and tumor removal under general anesthesia. In the operative field, a tumor, approximately $2.0 \times 2.5 \mathrm{~cm}$ in size, with encapsulation was observed in the left L3-4 facet joint. The tumor was completely resected from its facet joint adhesions with a safety margin. The tumor was firm and yellowish-red in color (Fig. 3A).

Histology of the facet joint showed collagenous tissue infiltration and proliferation of apparently benign spindle cells separated by collagen that are characteristics of desmoid tumors. The histologic findings were typical of benign infiltrative fibromatosis, desmoid tumors (Fig. 3B).

For 1 month, the patient performed rehabilitation exercises. Subsequently, his lower back pain, both buttock pain, and radiating pain in the left leg were significantly improved. Ten months after the operation, the patient had no neurologic deficit and no instability in following up radiography.

\section{DISCUSSION}

Desmoid tumors, also known as aggressive fibromatosis or musculoaponeurotic fibromatosis, are extremely rare, accounting for only $0.03 \%$ of all neoplasms ${ }^{4,7}$. The term fibromatosis covers a wide range of dysplastic lesions of connective tissue that are classified according to location as superficial and deep fibromatosis ${ }^{1}$. Deep fibromatosis is often referred to as a desmoid tumor. According to the World Health Organization classification, the term fibromatous tumor should be limited to those proliferations comprising fibers and cells stemming from fibroblasts ${ }^{17}$. Desmoid tumors grow locally and are invasive; thus, they are destructive but do not show metastasis,
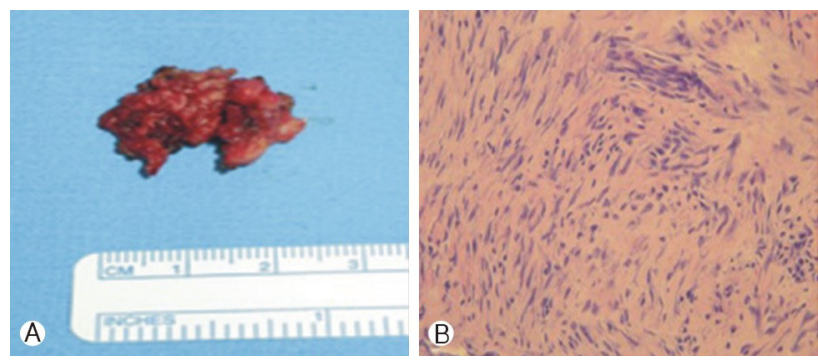

Fig. 3. Histopathologic findings, A: specimen of the yellowish red surface of a lumbar facet joint, B: benign, moderately cellular fibroblastic proliferation in a richly collagenized stroma (H\&E stain, $\times 200)$.

and are therefore often classified as semi-malignant ${ }^{17}$. Desmoid tumors have an annual incidence of 2-4 cases per million population $^{4,10,13,15)}$. The peak incidence is during the third decade of life. Although the term desmoid tumors were originally limited to fibromatosis involving the musculature of the anterior abdominal wall in post-partum women, it is now well recognized that such tumors arise at other sites. The etiology of these tumors is unknown. Trauma, hormonal stimulation, and genetic predisposition have all been implicated as the causes of desmoid tumors ${ }^{2,6,16,19)}$. Generally, desmoid tumors arise within scars or at the location of a previous injury. Therefore, the most commonly correlated etiological factor seems to be previous musculoaponeurotic trauma ${ }^{23)}$. Genetic abnormalities and steroid hormones are additional factors that may contribute to the genesis of these tumors ${ }^{1)}$. Genetic and cytogenetic studies have shown that trisomy 8 , trisomy 20 , or both, are the most common chromosomal abnormalities associated with fibromatosis ${ }^{8)}$. Hormonal involvement in the growth of desmoid tumors was suggested as early as $1935^{11,15)}$. Desmoid tumors have been experimentally induced by estrogen administration $^{21)}$. The growth rate roughly correlated with the level of endogenous estrogen in women of different age groups, suggesting that these tumors may indeed be under hormonal control $^{19)}$.

Desmoid tumors present a difficult diagnostic and therapeutic problem because of their high potential for aggressive local invasion and the high incidence of local recurrence (from $25 \%$ to $57 \%$ ) after primary excision ${ }^{22)}$. In addition, the tumor can regress spontaneously, but a more aggressive course and a higher incidence of recurrence has been observed in younger people $^{14)}$. Desmoid tumors are classified as semi-malignant, growing locally and invasively, and are thus destructive without showing metastasis. MRI is the imaging method of choice for both preoperative planning and post-management monitoring ${ }^{20)}$. Unexplained etiology and their various locations make the treatment of desmoid tumors difficult. Currently, there is no definitive and effective method of treatment. How- 
ever, most commonly, a wide surgical excision with a margin of clean tissue of approximately $1-2 \mathrm{~cm}$ remains the preferred method of initial treatment ${ }^{7,11}$. The surgical results for desmoid tumors, whether primary or recurrent, are not related to tumor size but to anatomic location and extension to vital structures such as spinal vessels and the spinal $\operatorname{cord}^{4,18)}$. In cases of limited surgery and radical resection of the tumor tissue, local irradiation is recommended ${ }^{5,13}$. The role of radiation therapy in an adjuvant setting, if any, is limited to the control of local recurrences ${ }^{3)}$. The role of adjuvant radiotherapy in patients with positive margins following resection of the primary disease is controversial, and should be based on potential morbidity from radiotherapy compared to the potential morbidity of another local recurrence. Some data suggest that postoperative radiation with 50-60 Gy may improve progression-free survival in incompletely excised tumors with acceptable morbidity ${ }^{3,10,12)}$. The effectiveness of chemotherapy and hormone therapy could not be verified; thus, both are used as alternatives in those cases in which adequate local treatment cannot be done ${ }^{15}$.

\section{CONCLUSION}

Desmoid tumors in the facet joints are very rare and until recently, few cases have been reported. For cases of well-limited resectable desmoid tumors of the facet joints, surgical removal is the best choice of treatment. However, it is very important to identify the onset of symptoms and determine whether additional radiation therapy and radiographic follow-up will need to be considered.

\section{REFERENCES}

1. Amin R: Desmoid tumour of the neck: Complete regression following radiation therapy. J Laryngol Otol 116(6):477-479, 2002

2. Ayala AG, Ro JY, Goepfert H, Cangir A, Khorsand J, Flake G: Desmoid fibromatosis: A clinicopathologic study of 25 children. Semin Diagn Pathol 3(2):138-150, 1986

3. Cardoso PF, da Silva LC, Bonamigo TP, Geyer G: Intrathoracic desmoid tumor with invasion of the great vessels. Eur J Cardiothorac Surg 22(6):1017-1019, 2002

4. Casillas J, Sais GJ, Greve JL, Iparraguirre MC, Morillo G: Imaging of intra- and extraabdominal desmoid tumors. Radiographics 11(6):959-968, 1991

5. Duda S, Bittner R, Laniado M, Lobeck H, Langer M: [imaging diagnosis of aggressive fibromatosis and the mrt-pathological correlation]. Rofo 151(1):57-62, 1989

6. Enzinger FM, Weiss SW: Soft tissue tumors, ed $2^{\text {nd }}$. St. Louis: Mosby, 1988

7. Ferenc T, Sygut J, Kopczynski J, Mayer M, Latos-Bielenska A, Dziki A, et al.: Aggressive fibromatosis (desmoid tumors): Definition, occurrence, pathology, diagnostic problems, clinical behavior, genetic background. Pol J Pathol 57(1):5-15, 2006

8. Fletcher JA, Naeem R, Xiao S, Corson JM: Chromosome aberrations in desmoid tumors. Trisomy 8 may be a predictor of recurrence. Cancer Genet Cytogenet 79(2):139-143, 1995

9. Gonatas NK: Extra-abdominal desmoid tumors. Report of six cases. Arch Pathol 71:214-221, 1961

10. Goy BW, Lee SP, Eilber F, Dorey F, Eckardt J, Fu YS, et al.: The role of adjuvant radiotherapy in the treatment of resectable desmoid tumors. Int J Radiat Oncol Biol Phys 39(3):659-665, 1997

11. Gronchi A, Casali PG, Mariani L, Lo Vullo S, Colecchia M, Lozza L, et al.: Quality of surgery and outcome in extra-abdominal aggressive fibromatosis: A series of patients surgically treated at a single institution. J Clin Oncol 21(7):1390-1397, 2003

12. Hoffmann W, Weidmann B, Schmidberger H, Niederle N, Seeber S, Bamberg M: [the clinical picture and therapy of aggressive fibromatosis (desmoids)]. Strahlenther Onkol 169(4):235-241, 1993

13. Kaplan J, Davidson T: Intrathoracic desmoids: Report of two cases. Thorax 41(11):894-895, 1986

14. Markhede G, Lundgren L, Bjurstam N, Berlin O, Stener B: Extraabdominal desmoid tumors. Acta Orthop Scand 57(1):1-7, 1986

15. Maurer F, Horst F, Pfannenberg C, Wehrmann M: Multifocal extra-abdominal desmoid tumor- -diagnostic and therapeutic problems. Arch Orthop Trauma Surg 115(6):359-362, 1996

16. McKinnon JG, Neifeld JP, Kay S, Parker GA, Foster WC, Lawrence W, Jr.: Management of desmoid tumors. Surg Gynecol Obstet 169(2):104-106, 1989

17. Oberthaler W, Rhomberg W: Aggressive fibromatosis. A rare cause for lumbar bulging. Arch Orthop Trauma Surg 107(6):388390, 1988

18. Park KY SD, Shin HC, Yoon DH, Kim KN: Surgical management of paraspinal tumors. Kor J Spine 4(3):134-139, 2007

19. Reitamo JJ, Scheinin TM, Hayry P: The desmoid syndrome. New aspects in the cause, pathogenesis and treatment of the desmoid tumor. Am J Surg 151(2):230-237, 1986

20. Sonmez E, Altinors N, Gulsen S, Ozen O: Extraabdominal desmoid tumor appearing following resection of thoracolumbar schwannoma. Turk Neurosurg 21(2):246-248, 2011

21. Wilcken N, Tattersall MH: Endocrine therapy for desmoid tumors. Cancer 68(6):1384-1388, 1991

22. Winer-Muram HT, Bowman LC, Parham D: Intrathoracic desmoid tumor: Ct and mri appearance. South Med J 87(10): 1007-1009, 1994

23. Wyler AR, Harris AB: Recurrent desmoid tumor following cervical laminectomy. Case report. J Neurosurg 39(1):114-116, 1973 